\title{
Molecular analyses and prognostic relevance of HPV in head and neck tumours
}

\author{
GIANNA BADARACCO ${ }^{1}$, CONSUELO RIZZO ${ }^{1}$, BARBARA MAFERA ${ }^{1,4}$, BARBARA PICHI ${ }^{2}$, \\ DIANA GIANNARELLI ${ }^{3}$, SIAVASH S. RAHIMI ${ }^{5}$, MAURIZIO G. VIGILI ${ }^{4}$ and ALDO VENUTI ${ }^{1}$ \\ ${ }^{1}$ Laboratory of Virology, ${ }^{2}$ Division of Otorhinolaringology, ${ }^{3}$ Biostatistical Unit, Regina Elena Cancer Institute; \\ ${ }^{4}$ Division of Otorhinolaringology, and ${ }^{5}$ Histopathology Service, San Carlo IDI-Hospital, Rome, Italy
}

Received September 18, 2006; Accepted October 24, 2006

\begin{abstract}
HPV involvement in head and neck (HN) cancer is still under active investigation. Fresh frozen and archival clinical samples from 115 patients affected by HN carcinomas were analysed by PCR-based methods and direct sequencing. HPV types, intra-type variants, physical status, viral load and viral transcript presence were determined. HPV positivity was correlated with the main clinical-pathological features, including smoker and drinker status, and the clinical outcome. Twenty-one tumours were HPV positive (18.3\%) with HPV16 being the most frequent type $(n=14)$ followed by HPV6 ( $n=4)$, HPV33, HPV35, and HPV58 ( $n=1$, each type). Tonsil carcinomas contained more high-risk HPV types $(6 / 8 ; 75 \%)$ than all other sites $(\mathrm{p}=0.0004)$. HPV16 genome was integrated in all analysed tumours, as pure integrated form or mixed with concomitant episomal forms (4 cases). The viral load showed a wide variability (range, 0.7-485 copies per cell) with the highest value detected in a larynx tumour and the lowest one in a case of cancer of the oral cavity. In 9 HPVpositive samples where mRNA was available, transcripts of viral early oncogenes originating by integrated, episomal or mixed forms of the viral genome were found. A statistically significant correlation was evidenced between HPV and tumour differentiation, being the virus more associated with tumour grade $\mathrm{G} 3 / \mathrm{G} 4$. Multivariate Cox regression analysis revealed that lymph-node and grade status were significant independent factors for a worse disease-free survival and overall survival, whereas the HPV status was associated with a better overall survival (OR, 0.33; 95\% CI, 0.13-0.81; $\mathrm{p}=0.01$ ). Taken together these results indicate that distinct pathological mechanisms for the malignant transformation in each single $\mathrm{HN}$ subsite should be taken in account; HPV molecular analyses should be considered a valid tool to distinguish subsets of oropharyngeal
\end{abstract}

Correspondence to: Dr Aldo Venuti, Laboratory of Virology, Regina Elena Cancer Institute, via Messi d'Oro 156, 00158 Rome, Italy

E-mail: venuti@ifo.it

Key words: HPV, head and neck tumour, integration, E6/E7 transcription, prognosis tumours and HPV presence could be useful for the prognostic assessment of HNSCC.

\section{Introduction}

Tumours of the oral cavity and pharynx have been estimated at 643,000 cases for 2002 , with 349,000 deaths (1). The incidence of these cancers is traditionally found to be very high in some areas of the world (e.g., France and South India), but in the last decade other areas (e.g., Eastern Europe and Japan) reported an increasing incidence of head and neck (HN) squamous cell carcinomas (SCC) (2). HN cancer constitutes one of the most difficult pathologies to eradicate. Recurrences are frequent and about a half of patients die (1). The heterogeneity of treatment response and the lack of prognostic factors could be the main causes of the adverse clinical outcome. Moreover, the behaviour variability of each individual tumour has also emphasized the difficulties of managing these tumours.

Life habits such as the intake of toxic agents present in tobacco smoke, alcohol drink and betel chewing, or poor hygiene remain major risk factors for these tumours. However, the fraction of $\mathrm{HN}$ cancers attributable to these risk factors is close to $80-90 \%$, while the remaining $15-20 \%$ of HNSCC patients lack typical tobacco or alcohol exposure.

A role for certain human papillomavirus (HPV), recognized causal agents in anogenital carcinogenesis (3), has been proposed for the development of the SCC from specific subsets of head and neck region, such as those from the oropharynx, with the tonsil being the most frequently infected site $(4,5)$. However, the presence of PCR-detectable HPV DNA is not always synonymous of an HPV-related aetiology, likely causing an overestimation in the number of cases.

A large number of studies has widely documented the association of HPV DNA with HNSCC $(4,5)$, whereas fewer studies, mostly focused on a small case number, are available of viral characteristics that are considered major determinants of HPV-associated carcinogenesis, i.e. viral oncogene expression (6-8), integration into cell genome (6,9-11), and viral load (10-12). Moreover, data on the simultaneous determination of all these viral characteristics are lacking.

The present study was aimed at contributing data on the relationship between HPV infection and HNSCC by determining the viral prevalence, intra-typic variants, physical status and mRNA expression. Furthermore, since a possible 
relevance of HPV presence has been reported in prognosis assessment (13) the correlation between viral infection and other prognostic factors for the disease outcome has been also analysed.

\section{Patients and methods}

Patients and samples. One hundred and thirty subjects, affected by head and neck lesions were enrolled in this study, but fifteen of them were excluded because the histological analysis did not detect any malignant lesion.

Fresh biopsies and 24 paraffin-embedded sections were obtained from these 115 patients, who underwent surgical treatment for a tumour in the head and neck region at the San Carlo Hospital and at the Regina Elena Cancer Institute. Ten of them were patients with precedent history of cancer, which presented recurrences of the disease at the time of HPV analyses.

Primary tumour samples were immediately snap-frozen in liquid nitrogen and stored at $-80^{\circ} \mathrm{C}$. We have previously reported on 65 of these cases, 16 of which contained HPV DNA and early oncogene transcripts (14). These 65 patients were included in the present study and analyzed for the viral load and physical status; an additional group of 50 patients was examined for the detection of the same viral parameters and of the viral transcripts. The study was approved by the ethics committee and an informed written consensus was gained by the participants.

Data collection. A database containing all clinical parameters at the time of diagnosis and risk factors such as smoke and alcohol consumption was constructed. Information on patients' tobacco and alcohol use was obtained from their medical files. Patients were classified as never or former/current daily tobacco smokers and/or alcohol drinkers independently of the drug dose over time. Former users were classified as at least 1 year of tobacco/alcohol abstinence.

Histopathological examination of the tumours was performed by an experienced pathologist. According to International Union Against Cancer (UICC) guidelines, tumours were classified by the tumour/node/metastasis (TNM) system and the histological grading assigned.

DNA and RNA extraction. Paraffin-embedded samples were de-waxed $2 \mathrm{x}$ in xylene for $10 \mathrm{~min}$ and re-hydrated throughout absolute ethanol dilutions. These re-hydrated samples and the fresh specimens of small size were lysed by proteinase $\mathrm{K}$ digestion and no further DNA/RNA extraction was performed. From the other specimens total DNA and RNA were simultaneously extracted by a commercial kit (Extract-All, Eurobio). RNA samples were further digested with Deoxyribonuclease I Amplification grade (Invitrogen) for $15 \mathrm{~min}$ at room temperature. Enzyme was inactivated by the addition of EDTA and incubation at $65^{\circ} \mathrm{C}$ for $10 \mathrm{~min}$. RNA was precipitated in two volumes of absolute ethanol containing $0.3 \mathrm{M}$ sodium acetate $\mathrm{pH} 5.2$ and $20 \mu \mathrm{g} / \mathrm{ml}$ of linear acrylamide, as carrier. The RNA pellet was resuspended in $20 \mu 1$ of RNAse-free water.

The adequacy of the samples and the absence of PCR inhibitors were monitored by preliminary PCR amplifications with primers recognizing the human $\beta$-globin gene for the DNA, and with primers for the glyceraldehyde-3-phosphatedehydrogenase (GAPDH) gene for the RNA. These primers were designed with the Beacon Designer 2.0 Software (BioRad).

HPV detection and typing. HPV detection was achieved by PCR with the consensus primers MY09/MY11 and GP5+/GP6 ${ }^{+}$ as already reported (14). Briefly, the PCR conditions were $1.5 \mathrm{mM} \mathrm{MgCl} 2$ for MY09/MY11 or $3 \mathrm{mM} \mathrm{MgCl}_{2}$ for $\mathrm{GP}^{+} /$ $\mathrm{GP}^{+}, 200 \mu \mathrm{M}$ dNTPs, $0.5 \mu \mathrm{M}$ for each primer and $2.5 \mathrm{U}$ of Platinum TaqDNA polymerase (Invitrogen) in a final reaction volume of $50 \mu \mathrm{l}$. In each amplification, positive and negative controls (100 ng of CaSki cell line DNA and no DNA, respectively) were added. PCR products were electrophoresed through $2 \%$ agarose gel and visualised by ethidium bromide staining under ultraviolet light. Typing of the HPV-positive samples was performed by automated sequencing of the amplified products (Biogen GeneLab, Italy) and by type specific amplification with selected primers for the E6 region of HPV16 (6). Sequence analyses of the positive samples were performed using the BLAST programme (http://www. ncbi.nlm.nih.gov/BLAST).

Viral load. To determine the number of input cells per test, each sample underwent quantification of the house-keeping ß-globin gene. HPV load was expressed as the number of copies per cell assuming that one copy of the B-globin gene corresponds to one cell genome. The same region amplified by GP primers for genotyping was chosen for real-time PCR performed in the I Cycler apparatus (BioRad). Viral load was determined with the IQ ${ }^{\mathrm{TM}}$ SYBR-Green Supermix (BioRad) according to the manufacturer's instructions, with a magnesium concentration of $3 \mathrm{mM}$, a primer concentration of $500 \mathrm{nM}$ in a final reaction volume of $25 \mu \mathrm{l}$. PCR temperatures and cycle numbers were the same as for genotyping determination. A standard curve was constructed with seven 5-fold serial dilutions of a reference HPV16-plasmid starting from $1.94 \times 10^{7}$ copies. To verify the specificity of the reaction, the PCR product underwent a $\mathrm{T}$ melting curve analysis, starting from the annealing temperature up to $95^{\circ} \mathrm{C}$, with $0.5^{\circ} \mathrm{C} / 10 \mathrm{sec}$ increases.

Physical status of viral genome. The integration of HPV16 and HPV18 was detected essentially as already published in a study on HPV physical status in genital tumours where the technical conditions are described in detail (15). Briefly, to distinguish the pure integrated viral forms from the circular form, the integrity of HPV16 or HPV18 genomes was analysed by amplifications with type specific primers recognizing the almost entire E1 and E2 sequences that are the regions most frequently disrupted or deleted during the viral integration into the cell genome. To determine the concurrent presence of episomal and integrated HPV16 DNA (i.e. mixed forms), samples with an intact E2 sequence were re-amplified in multiplex PCRs with primers for E6 and E2 using a method based on the determination of the relative ratio of E2 to E6 amplified products (E2/E6 ratio) (16).

In some HPV-positive cases the multiply primed rollingcircle amplification (RCA) method (17) was utilized to confirm 
the presence of viral episomal forms. This method utilizes the \$29 DNA polymerase with random hexamer primers to amplify the circular DNA virus genomes without the need for prior knowledge of their DNA sequences. Multiply primed RCA was performed with the TempliPhi 100 amplification kit (Amersham Biosciences) according to the manufacturer's instructions. Two micrograms of extracted DNA was transferred into a $0.5-\mathrm{ml}$ tube with $5 \mu 1$ of TempliPhi sample buffer with $450 \mu \mathrm{M}$ extra dNTPs, and $0.2 \mu \mathrm{l}$ of TempliPhi enzyme mix, containing the $\Phi 29$ DNA polymerase and exonuclease-protected random hexamers in $50 \%$ glycerol. The samples were denatured at $95^{\circ} \mathrm{C}$ for 3 min and afterwards were placed on ice. The reaction mixtures were incubated overnight (approximately $16 \mathrm{~h}$ ) at $30^{\circ} \mathrm{C}$. Afterwards, the reaction mixtures were put on ice, subsequently heated to $65^{\circ} \mathrm{C}$ for $10 \mathrm{~min}$ to inactivate the $\Phi 29$ DNA polymerase, and stored at $-20^{\circ} \mathrm{C}$ until further analysis. Two microliters of the multiply primed RCA products were digested with $10 \mathrm{U}$ of BamHI, a single cutter of the HPV16 complete genome, and resolved in ethidium bromide stained agarose gel. Negative control samples were made with buffer without the TempliPhi enzyme.

Expression of viral transcripts from early genes. RNA (300 ng) was reverse transcribed using $0.5 \mu \mathrm{M}$ of the antisense HPV16 E7 primer AS858 (5'-TTATGGTTTCTGAGAACA GAT-3') or of an oligo(dT) $)_{17}$-primer coupled to a linker sequence $\left[(\mathrm{dT})_{17}-\mathrm{p} 3,5\right.$ '-GACTCGAGTCGACATCGATTTT TTTTTTTTTTTTT-3'] and 200 units of Omniscript Reverse Transcriptase (Qiagen) for $1 \mathrm{~h}$ at $42^{\circ} \mathrm{C}$ in a final volume of $20 \mu 1$. To rule out the presence of contaminating DNA in RNA samples, all the assays were performed both with and without reverse transcriptase. Positive samples were made from CaSki and SiHa cell lines. The synthesized cDNA underwent PCR analysis by three different procedures: i) an in-house method for detection of the HPV16/E7 gene expression; ii) a procedure that allows the detection of early transcripts from episomal virus; and iii) a method for the amplification of papillomavirus oncogene transcripts (APOT) from integrated and/or episomal genome.

i) Sense primer S562 (5'-ATGCATGGAGATACACCT AC-3') and the antisense AS858 were used for amplification of the 296-bp product of the E7 gene from position 562 to 858 of the complete HPV16 genome. The primers described by Sasagawa et al (18) were utilised for the amplification of transcripts of HPV6 and HPV33. The $50 \mu 1$ mixture included $5 \mu \mathrm{l}$ of the previous reverse transcription reaction, $2.5 \mathrm{U}$ Platinum TaqDNA polymerase (Invitrogen), $1.5 \mathrm{mM} \mathrm{MgCl}_{2}$ and $0.5 \mu \mathrm{M}$ of each primer. Samples were incubated at $94^{\circ} \mathrm{C}$ for $1 \mathrm{~min}, 42^{\circ} \mathrm{C}$ for $1 \mathrm{~min}$ and $72^{\circ} \mathrm{C}$ for $1 \mathrm{~min}$ (30 cycles) followed by a final extension at $72^{\circ} \mathrm{C}$ for $5 \mathrm{~min}$. PCR products were electrophoresed through $2 \%$ agarose gel and visualised by ethidium bromide fluorescence emission.

ii) Early transcripts from episomal HPV were detected with primers (P1 and P2) for un-translated sequences adjacent to poly(A) tail and for E5 exon, followed by a nested PCR with internal E5 primers (P3 and P4), essentially as described by Biswas et al (19). Briefly, primers P1 and P2 were used in the first-round amplification to produce a 421-bp amplicon. Nested PCR employed primers P3 and P4 to produce an amplicon of 202 bp. Final PCR products were visualized in ethidium bromide staining agarose gel.

iii) cDNAs encompassing poly(A) tail and the E7 gene were amplified according to the protocols of Klaes et al (20). Briefly, a nested PCR was made using HPV16 E7-specific oligonucleotides p1-16 and p3 in the first amplification and primers p2-16 and (dT) ${ }_{17}-\mathrm{p} 3$ in the second PCR. In order to distinguish the transcripts from integrated or episomal viral genomes, Southern blot filter of the final amplified products was hybridized with HPV16 E7 specific probe (h1-16), always retained during integration, and a second parallel filter with E4-specific probe (h2-16), often deleted during integration. Digoxigenin (DIG)-labelling and detection of the probes was performed with the ECL oligolabelling and detection kit (Pharmacia Biotech) according to the manufacturer's instructions.

Statistics. Associations between discrete variables were tested by $\chi^{2}$ analysis or Fisher's exact test. Overall survival (OS) was calculated from the date of surgery to the date of last follow-up or death from any cause. Disease-free survival (DFS) was calculated from the date of surgery to the date of tumour relapse or to the date of last follow-up. Comparison of variables with potential prognostic value on DFS and OS was made using the log-rank test in univariate analysis with SPSS software. Independent prognostic factors with major impact on overall survival and disease-free survival time were studied in multivariate analysis using Cox proportional hazard model and risk ratios were obtained with I model. Statistical significance was established to be $\mathrm{p} \leq 0.05$.

\section{Results}

Clinical-pathological features and HPV detection. The clinicalpathological features of patients and the alcohol/smoke use are shown in Table I. The subjects were 86 men and 29 women (mean age, 63.21 years $\pm 13.53 \mathrm{SD}$; range, 33-84). The majority of patients were over $50(80 \%)$. A high percentage of patients were smokers $(67 \%)$ whereas the alcohol drinkers represented only $43 \%$, including 20 and 3 past users, respectively.

Tumours were localized mostly in the oral cavity $(n=60)$, followed by the larynx $(n=30)$, the oropharynx $(n=10)$, the tonsil area $(n=8)$, the hypopharynx $(n=5)$ and the sinus/nose $(n=2)$. Almost all the tumours were classified as SCC $(n=111)$, only 1 was diagnosed as verrucous carcinoma and 3 as carcinoma in situ. Histological grading showed a higher number of well and moderately differentiated SCC (grade G1 and G2) than poorly or undifferentiated SCC (grade G3 and $\mathrm{G} 4)$. The major number of tumours scored T2 (41\%) for cancer size, N0 for lymph-node involvement (52\%), and M0 $(67 \%)$ for metastases.

HPV detection was achieved with MY or GP primers; a sample was assigned positive when the presence of HPV DNA was detected with at least one of these primer sets (Table I). The PCR analysis of the 115 patients revealed the presence of HPV in 21 tumours with a $18.26 \%$ of positivity.

Patients in the HPV-positive group tended to be women (20.0\% versus $17.4 \%)$, younger than 50 (26.1\% versus $16.3 \%)$, no-smokers $(26.3 \%$ versus $14.3 \%)$ and no-drinkers $(20.0 \%$ 
Table I. Demographic and clinical-pathological characteristics of patients by HPV status.

\begin{tabular}{ccc}
\hline Patients & HPV positive HPV negative p-value \\
$(\%)$ & $(\%)$ & $(\%)$
\end{tabular}

\begin{tabular}{lrrr}
\hline Gender & & & \\
Female & $29(25.2)$ & $6(20.7)$ & $23(79.3)$ \\
Male & $86(74.8)$ & $15(17.4)$ & $71(82.6)$ \\
Age & & & \\
$\leq 50$ years & $23(20.0)$ & $6(26.1)$ & $17(73.9)$ \\
$>50$ years & $92(80.0)$ & $15(16.3)$ & $77(83.7)$
\end{tabular}

ns

Smoke

$\begin{array}{llll}\text { yes } & 77(67.0) & 11(14.3) & 66(85.7) \\ \text { no } & 38(33.0) & 10(26.3) & 28(73.7)\end{array}$

Alcohol

yes

$50(43.5) \quad 8(16.0)$

$42(84.0)$

no

$65(56.5) \quad 13(20.0)$

$52(80.0)$

Tumour site

Oral cavity

$60(52.2)-8(13.3)$

Sinus/nose

Oropharynx

$$
2(1.7)
$$

Tonsil

$10(8.7)$

Hypopharynx

$8(7.0)$

$2(100.0)$

0

$6(75.0)$

$5(4.3)$

$1(20.0)$

$30(26.1)$

$4(13.3)$

Histology

$\begin{array}{lccc}\mathrm{SCC} & 111(96.6) & 20(18.0) & 91(82.0) \\ \text { Ca } \text { in situ } & 3(2.6) & 1(33.3) & 2(66.7) \\ \text { Verrucous ca } & 1(0.8) & 0 & 1(100.0)\end{array}$

Histological grade of SCC

$\begin{array}{lccc}\text { G1 } & 7(6.3) & 0 & 7(100.0) \\ \text { G2 } & 59(53.2) & 6(10.2) & 53(89.8) \\ \text { G3 } & 42(37.8) & 13(31.0) & 29(69.0) \\ \text { G4 } & 3(2.7) & 1(33.3) & 2(66.7)\end{array}$

TNM

\begin{tabular}{lcrrr} 
T1 & $27(24.1)$ & $2(7.4)$ & $25(92.6)$ & \\
T2 & $46(41.1)$ & $10(21.7)$ & $36(78.3)$ & \\
T3 & $26(23.2)$ & $5(19.2)$ & $21(80.8)$ & \\
T4 & $13(11.6)$ & $3(23.1)$ & $10(76.9)$ & \\
N0 & $58(51.8)$ & $8(13.8)$ & $50(86.2)$ & $n s$ \\
N+ & $48(42.9)$ & $10(20.8)$ & $38(79.2)$ & \\
Nx & $6(5.3)$ & $2(33.3)$ & $4(66.7)$ & \\
M0 & $78(69.6)$ & $11(14.1)$ & $67(85.9)$ & $n s$ \\
M1 & $1(0.9)$ & $1(100)$ & 0 & \\
Mx & $33(29.5)$ & $8(24.2)$ & $25(75.8)$ & \\
\hline
\end{tabular}

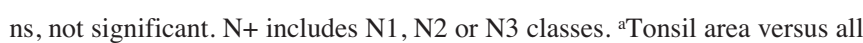
other sites, ${ }^{\mathrm{b}} \mathrm{G} 3-\mathrm{G} 4$ versus $\mathrm{G} 1-\mathrm{G} 2$. versus $16.0 \%$ ). Univariate analysis comparing these data with those in the HPV-negative group failed to demonstrate a statistically significant association of HPV infection with these parameters.

Histopathological correlation of HPV with tumours showed that the frequency of HPV positivity varied among different anatomical sites: 8 of $60(13 \%)$ in the oral cavity, 2 of 2 $(100 \%)$ in the sinus/nose, 6 of $8(75 \%)$ in the tonsil, 1 of 5 $(20 \%)$ in the hypopharynx, and 4 of $30(13 \%)$ in the larynx, while none of the 10 oropharynx tumours resulted HPVpositive. These differences were statistically significant, the tonsil area being significantly more infected with respect to all other sites $(\mathrm{p}=0.0004)$.

In terms of degree of atypia of the HPV-positive specimens, 6 SCC had grade G2, 13 had grade G3, 1 had grade G4 and no patients had grade G1 malignancies. Of the HPV-negative specimens, the number of patients with grade $1,2,3$, and 4 SCC was 7, 53, 29, and 2, respectively. There was a statistically significant association between presence of HPV and grade $\mathrm{G} 3-\mathrm{G} 4$ ( $\mathrm{p}=0.005$ versus grade $\mathrm{G} 1-\mathrm{G} 2$ ).

The presence of HPV DNA had no statistically significant association with histology or TNM stages.

Molecular analysis of HPV DNA. HPV genotyping was achieved by type specific PCR and direct sequencing. The results of these analyses by anatomical sites are presented in Fig. 1.

Seventeen out of the 21 positive tumours $(81.0 \%)$ were infected by the high-risk HPV16, 33, 35 and 58 types. The remaining tumours were all infected by the low-risk HPV6 type $(4 / 21 ; 19.0 \%)$. HPV16 was the predominant type detected in 5 SCC of the oral cavity $(62.5 \%), 1$ of the sinus/nose $(50 \%), 5$ of the tonsil $(83.3 \%)$, and 3 of the larynx $(75 \%)$ with an overall positivity of $66.7 \%$. HPV6 DNA was detected in one carcinoma in situ of the oral cavity, one of the nasal vestibule, one of the hypopharynx and one of the larynx. HPV33, and HPV58 were detected in oral cavity tumours, one case each, and HPV35 was revealed in one tonsil tumour. Despite the difficulty to discriminate the European German from the East Asian variant by the sequencing of a fragment of the L1 region, the alignment of the sequences with the Gene Bank Data Base revealed the presence of the following HPV16 variants: European German 131 (9 cases), African type 2 (2 cases), Asian-American (1 case), and unclassified variant (1 case).

In Table II are reported data on the viral load and physical status together with the clinical-pathological features of the HPV-positive patients. The quantity of DNA extracted from the various samples hampered to perform all the possible analyses in all specimens. The viral load was determined in 12 out of 21 positive samples with a copy number ranging from 0.7 to 485 per one- $\beta$-globin gene. The highest value was detected in an HPV6-positive larynx tumour whereas the lowest one was from an HPV16-positive tumour of oral cavity. The physical status was ascertained in 16 samples by E1-E2 specific and multiplex PCR for HPV16, and by RCA for all HPVs. HPV genome was detected in pure integrated form in 8 HPV16 samples while mixed forms (i.e. integrated plus episomal) were revealed in 4 specimens. By the anatomical sites the mixed forms were never detected in the larynx 


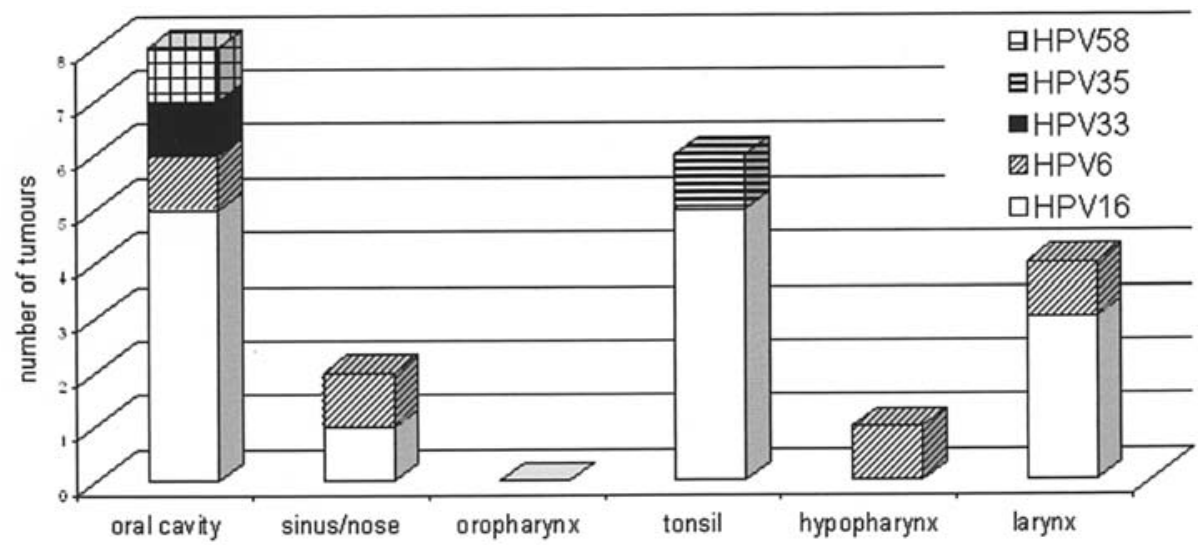

Figure 1. HPV types by tumour site. All the tumours have been grouped according to different anatomical sites. The HPV genotyping was performed by direct sequencing of the amplified products as described in Materials and methods.

Table II. HPV-positive patients: clinical parameters, life habits and viral factors.

\begin{tabular}{|c|c|c|c|c|c|c|c|c|c|c|c|c|}
\hline \multirow{2}{*}{$\begin{array}{l}\text { Patient } \\
\text { code }\end{array}$} & \multirow[t]{2}{*}{ Gender } & \multirow[t]{2}{*}{ Age } & \multirow[t]{2}{*}{ Tumour site } & \multirow[t]{2}{*}{ Histology } & \multirow{2}{*}{$\begin{array}{l}\text { Tumour } \\
\text { grade }\end{array}$} & \multirow[t]{2}{*}{ TNM } & \multirow[t]{2}{*}{ Smoke } & \multirow[t]{2}{*}{ Alcohol } & \multirow{2}{*}{$\begin{array}{l}\text { HPV } \\
\text { type }\end{array}$} & \multirow{2}{*}{$\begin{array}{c}\text { Viral } \\
\text { copy/cell }\end{array}$} & \multicolumn{2}{|c|}{ Physical status } \\
\hline & & & & & & & & & & & Multiplex & $\mathrm{RCA}$ \\
\hline 277 & M & 46 & oral cavity & SCC & G2 & T2N0M0 & no & no & 33 & na & & na \\
\hline 294 & $\mathrm{~F}$ & 40 & oral cavity & SCC & G3 & T4N2M0 & yes & yes & 16 & na & integrated & - \\
\hline 363 & $\mathrm{~F}$ & 82 & oral cavity & SCC & G3 & T3N0M0 & no & no & 16 & 27 & mixed & na \\
\hline 420 & M & 64 & oral cavity & SCC & $\mathrm{G} 2$ & $\mathrm{~T} 3 \mathrm{~N} 2 \mathrm{Mx}$ & yes & no & 58 & na & & + \\
\hline 421 & M & 37 & oral cavity & SCC & G2 & T1N0M0 & no & no & 16 & 0.7 & integrated & - \\
\hline 425 & $\mathrm{~F}$ & 76 & oral cavity & $\mathrm{Ca}$ in situ & & & yes & yes & 6 & na & & na \\
\hline 430 & $\mathrm{~F}$ & 75 & oral cavity & SCC & G2 & $\mathrm{T} 2 \mathrm{~N} 2 \mathrm{Mx}$ & no & no & 16 & 132 & integrated & - \\
\hline 438 & $\mathrm{~F}$ & 69 & oral cavity & SCC & G3 & T4NxM0 & no & no & 16 & 391 & mixed & + \\
\hline 278 & M & 36 & nasal sinus & SCC & G4 & T3NxM0 & yes & yes & 16 & na & na & na \\
\hline 287 & M & 47 & nasal vestibule & SCC & G3 & T2N0M0 & yes & no & 6 & na & & + \\
\hline 285 & M & 53 & tonsil & SCC & G3 & $\mathrm{T} 2 \mathrm{~N} 2 \mathrm{Mx}$ & no & yes & 16 & 182 & mixed & + \\
\hline 400 & M & 83 & tonsil & SCC & G3 & $\mathrm{T} 2 \mathrm{~N} 2 \mathrm{Mx}$ & no & yes & 16 & 392 & mixed & + \\
\hline 401 & M & 67 & tonsil & SCC & G3 & $\mathrm{T} 3 \mathrm{~N} 2 \mathrm{Mx}$ & no & no & 16 & 100 & integrated & - \\
\hline 403 & M & 70 & tonsil & SCC & G3 & $\mathrm{T} 3 \mathrm{~N} 2 \mathrm{Mx}$ & yes & no & 16 & 130 & integrated & - \\
\hline 418 & M & 45 & tonsil & SCC & G3 & $\mathrm{T} 2 \mathrm{~N} 2 \mathrm{Mx}$ & no & no & 16 & 84 & integrated & - \\
\hline 440 & M & 81 & tonsil & SCC & G3 & $\mathrm{T} 2 \mathrm{~N} 2 \mathrm{M} 0$ & no & no & 35 & 336 & & + \\
\hline 298 & M & 70 & hypopharynx & SCC & G3 & T4N3Mx & yes & yes & 6 & 140 & & na \\
\hline 271 & M & 76 & larynx & SCC & G3 & T2N0M1 & yes & no & 16 & na & na & na \\
\hline 282 & $\mathrm{~F}$ & 67 & larynx & SCC & $\mathrm{G} 2$ & T2NOM0 & yes & no & 16 & na & integrated & - \\
\hline 518 & M & 63 & larynx & SCC & G3 & T1N0M0 & yes & yes & 16 & na & integrated & - \\
\hline 558 & M & 60 & larynx & SCC & $\mathrm{G} 2$ & T2NOM0 & yes & yes & 6 & 485 & & + \\
\hline
\end{tabular}

na, not available.

tumours. RCA analysis confirmed the results of the HPV16 samples with the detection of circular DNA in the mixed samples and revealed the presence of episomal forms in the HPV6, 35 and 58 infected samples. In these samples the presence of concomitant integrated genomic forms could not be defined.
$H P V$ expression. Suitable RNA for PCR was obtained from 9 HPV-positive samples, as demonstrated by the amplification of the house-keeping gene GAPDH (Table III). The presence of transcripts was detected by RT-PCR with specific primers for the E5 and E7 gene of HPV16 and for the E6 gene of the other HPVs. For the HPV16-positive samples APOT analysis 
Table III. mRNA expression of HPV oncogenes.

\begin{tabular}{|c|c|c|c|c|c|c|c|}
\hline \multirow[t]{2}{*}{ Patient code } & \multirow[t]{2}{*}{ HPV type } & \multirow[t]{2}{*}{ GAPDH } & \multirow[t]{2}{*}{ HPV16 E5 } & \multirow[t]{2}{*}{ HPV16 E7 } & \multicolumn{2}{|c|}{ HPV16-APOT } & \multirow{2}{*}{$\begin{array}{l}\text { Type specific E6 } \\
\text { for non-HPV16 }\end{array}$} \\
\hline & & & & & Integrated & Episomal & \\
\hline 282 & HPV16 & pos & pos & pos & pos & neg & \\
\hline 285 & HPV16 & pos & pos & pos & pos & pos & \\
\hline 294 & HPV16 & pos & neg & pos & pos & neg & \\
\hline 363 & HPV16 & pos & pos & pos & pos & pos & \\
\hline 438 & HPV16 & pos & pos & pos & pos & pos & \\
\hline 287 & HPV6 & pos & & & & & neg \\
\hline 298 & HPV6 & pos & & & & & neg \\
\hline 558 & HPV6 & pos & & & & & pos \\
\hline 440 & HPV35 & pos & & & & & pos \\
\hline
\end{tabular}

pos/neg, presence/absence of viral transcripts.

Table IV. Association among clinical features, life habits, HPV status and clinical outcome

\begin{tabular}{|c|c|c|c|c|}
\hline & $\begin{array}{c}\text { DFS at } \\
2 \text { years }(\%)\end{array}$ & p-value & $\begin{array}{c}\text { OS at } \\
2 \text { years }(\%)\end{array}$ & p-value \\
\hline Gender & & 0.73 & & 0.45 \\
\hline Female & 58.3 & & 64.8 & \\
\hline Male & 54.0 & & 71.8 & \\
\hline Age & & 0.77 & & 0.66 \\
\hline$\leq 50$ & 60.2 & & 79.1 & \\
\hline$>50$ & 53.9 & & 68.0 & \\
\hline Smoke & & 0.43 & & 0.8 \\
\hline yes & 50.3 & & 68.8 & \\
\hline no & 63.8 & & 72.3 & \\
\hline Alcohol & & 0.47 & & 0.54 \\
\hline yes & 51.6 & & 80.5 & \\
\hline no & 58.6 & & 67.0 & \\
\hline Tumour site & & 0.81 & & 0.25 \\
\hline oral cavity & 54.3 & & 67.7 & \\
\hline oropharynx + tonsil & 62.3 & & 62.3 & \\
\hline larynx & 47.2 & & 74.3 & \\
\hline Tumour grade & & 0.006 & & 0.002 \\
\hline $\mathrm{G} 1-\mathrm{G} 2$ & 63.7 & & 79.9 & \\
\hline G3-G4 & 38.9 & & 52.3 & \\
\hline Tumour size & & 0.03 & & 0.08 \\
\hline $\mathrm{T} 1-\mathrm{T} 2$ & 60.8 & & 76.5 & \\
\hline T3-T4 & 41.7 & & 56.1 & \\
\hline Node status & & 0.005 & & 0.0001 \\
\hline neg & 67.5 & & 89.3 & \\
\hline pos & 39.6 & & 50.4 & \\
\hline HPV & & 0.26 & & 0.61 \\
\hline neg & 53.2 & & 70.6 & \\
\hline pos & 66.1 & & 75.9 & \\
\hline
\end{tabular}

was performed in order to detect the simultaneous presence of transcripts from integrated and episomal genomic forms by measuring the transcript length and by hybridisation with specific probes for the E7 and E4 region. Viral transcripts encompassing E6 or E7 early genes were detected in all HPV16-positive samples, in the HPV35-positive specimen and in only 1 out of 3 HPV6-positive tumours. Sequences of the E5 genes of HPV16, often deleted during integration, were not detected in one sample, suggesting viral integration. APOT assay revealed the presence of transcripts derived from integrated sequences in all 5 samples, whereas the simultaneous presence of transcripts derived from episomal sequences were revealed in 3 specimens. In sample 282 the APOT analysis revealed the presence of shorter transcripts hybridising with both E7 and E4 probes, consistent with the presence of transcripts for the E5 gene (data not shown).

Survival analysis. Follow-up data were available from 103 of the 115 patients (Table IV). The median duration of follow-up of the patients alive at last follow-up was 12 months with a range of 1 to 66 months.

Overall, the DFS at 2 years was $53.4 \%$. Presence of HPV was not significantly associated with DFS at 2 years $(53.2 \%$ of HPV-negative patients versus $66.1 \%$ of HPV-positive ones; $\mathrm{p}=0.26)$ as well as gender $(\mathrm{p}=0.73)$, age $(\mathrm{p}=0.77)$, tumour site $(\mathrm{p}=0.81)$, smoker $(\mathrm{p}=0.43)$ and drinker $(\mathrm{p}=0.47)$ status. On the contrary, the G3-4 ( $p=0.006, \mathrm{G} 1-2$ versus G3-4), $\mathrm{T}(\mathrm{p}=0.03$, T1-2 versus $\mathrm{T} 3-4)$, and $\mathrm{N}+(\mathrm{p}=0.005, \mathrm{~N} 0$ versus $\mathrm{N}+)$ status were highly significantly associated with DFS. Overall survival analysis revealed a significant association of $G(p=0.002$, G1-2 versus G3-4) and N ( $\mathrm{p}=0.0001$, N0 versus $\mathrm{N}+$ ) status with a worse prognosis; whereas the HPV presence was associated with a better prognosis but this association was not statistically significant in univariate analysis $(\mathrm{p}=0.61)$. The remaining clinical and pathological characteristics were also not statistically significant.

In a Cox regression model of multivariate analysis the $\mathrm{G}$ status was confirmed to be associated with DFS (OR, 2.91; 95\% CI, 1.15-7.36; $\mathrm{p}=0.02)$ and $\mathrm{OS}(\mathrm{OR}, 2.64 ; 95 \% \mathrm{CI}$, 
1.27-5.48; $\mathrm{p}=0.009)$. The lymph node involvement was also firmly associated with DFS (OR, 6.22; 95\% CI, 1.74-22.18; $\mathrm{p}=0.005)$ and $\mathrm{OS}$ (OR, 2.24; 95\% CI, 1.05-4.80; $\mathrm{p}=0.04)$. The presence of HPV DNA still was not associated with DFS (OR, 0.33; 95\% CI, 0.11-1.05; $\mathrm{p}=0.06$ ) whereas an association with OS was demonstrated with high significance (OR, 0.33; 95\% CI, 0.13-0.81; $\mathrm{p}=0.01$ ), indicating a better prognosis for the patients harbouring HPV-positive tumours. The multivariate analysis did not reveal any other association among the clinicalpathological parameters analysed (data not shown).

\section{Discussion}

Evidence supports an etiological role for HPV in a subset of oropharyngeal SCC, especially those originating in the tonsil. However, to date, the numerous existing studies, performed by sensitive PCR-based detection methods, have shown variable frequencies of the HPV prevalence in HN tumours either for all sites and for each single subsite. Some authors failed to reveal high HPV prevalence level in countries with a high incidence of HN cancers, demonstrating a scarce contribution of HPV in carcinogenesis $(21,22)$ while others even reported the absence of HPV DNA in a Chinese population, though of small size (23). Reasons of these oscillations seem to be ascribed to population variability, ethnic factors and anatomic location as well as recognised exposures to risk factors such as smoking and alcohol, more than methodological differences $(4,24)$.

In the present study the HPV prevalence rate for all $\mathrm{HN}$ sites was $18.3 \%$; this percentage is slightly lower than that recently reported by Kreimer et al (4), who estimated a worldwide mean value of $25.9 \%$ in the systematic review of studies conducted in a large number of countries. In addition, in the previous study performed with the same PCR detection methods on a smaller number of patients we detected a higher level (25.6\%) of HPV positivity (14). This difference could be explained by the influence of study size since it was reported an inverse correspondence between HPV prevalence and number of cases examined. The source of samples may also contribute to variability in prevalence, although the above mentioned meta-analysis seems to exclude this possibility. Indeed, the presence of paraffin-embedded samples in our study did not affect our HPV prevalence data because the same value of positivity was recorded by including solely fresh/frozen samples.

Our data on the HPV positivity pattern for single subsites indicate a trend of increasing HPV prevalence rate with the highest statistically significant value for the tonsil. This finding is more consistent with published data, although the percentages for single sites are still slightly different from those reported for Europe (4). In particular, the high frequency detected in tonsil tumours confirms the hypothesis on the relevance of the anatomic site in determining the susceptibility to infection.

HPV16, the most common HPV type detected in biopsies from women with cervical SCC, was the most common type detected in biopsies from our case series of HNSCCs. In the oropharynx, HPV16 accounted for the majority of HPVpositive cases with a hot-spot in the tonsil area (5 out of 6 , $83 \%$ ), whereas its presence was less striking in other HN subsites. The analysis of HPV16 variants indicates a large predominance of the European variant as expected from the regional provenience of the patients (data not shown).

HPV18, the second most common type detected in HPVpositive cancers of cervix was never detected in our samples. The extreme rarity of HPV18 in the oropharynx was already reported in the majority of published studies (4). The authors speculated that since HPV18 has a special tropism for glandular tissue and is frequently detected in adenocarcinomas, its low prevalence may be related to the rarity of these tumours in oropharynx. Other oncogenic HPV types (e.g., HPV33, 35, and 58), commonly detected in invasive cervical cancer biopsies, were rarely detected in our HNSCC biopsies. On the contrary, the 'low-risk' HPV6, that causes benign tumours in the aerodigestive and genital tract (3), was present in a significant number of our HNSCCs $(19 \%)$; this percentage is greater than any of the oncogenic types other than HPV16. However, the sole detection of viral DNA in biopsy material is not evidence of disease causation. Our data on viral expression clearly indicate that the mRNA of HPV6 was present in a single case, in contrast to that of the high-risk types that was always detected. Therefore, HPV types that are lacking the ability to induce neoplastic transformation may be infecting the tumour and acting as a passenger rather than driver of tumourigenesis. Nevertheless, it is worth noting that the unique transcriptionally active HPV6-positive case was from a larynx tumour of a patient with a precedent history of laryngeal papillomatosis, a lesion that in a certain proportion of cases may undergo malignant progression (25).

Expression of E6/E7 rather than the presence of HPV DNA is an important indicator of viral activity, supporting a biologic role of HPV16 in the carcinogenesis by interaction with cellular gene products such as $\mathrm{p} 53, \mathrm{pRb}$ and p16INK4A $(5,26)$. In all the HPV16-positive tumours where the RNA was available, the presence of viral mRNA was detected, indicating that the HPV DNA was always transcriptionally active. In contrast, other authors reported the lack of HPV16 expression in some tumours, mostly of the oral cavity (8). The presence of transcripts from integrated viral genome was detected in HPV16 samples and in some of them the concomitant expression of mRNA from episomal genome was also detected. Transcripts from both integrated and episomal genome in tumour clinical samples were reported occasionally (27). Mixed transcripts were detected in a cell line derived from tongue-base tumour (28), suggesting that the presence of both transcripts in our samples may derive from the same tumour cell rather than from different cell populations within the tumour.

Integration of the viral genome into the tumour cell genome is a further indicator of a causal involvement of HPV in tumourigenesis, since HPV DNA integration in cervical cancer usually results in the disruption of the E1 and E2 ORFs, the products of which are repressors of E6/E7 transcription. In our HNSCC, the integration state of HPV was assayed with different methodologies that gave concordant results and indicated that HPV16 was always integrated into the cell genome and in a third of cases in association with episomal forms. The integration of HPV was previously described in HPV16-positive tumours but with a lower percentage of mixed forms (11). Mixed forms of HPV16 were reported in cervix carcinoma and their presence in HNSCC reinforces 
the similarity of the carcinogenic process driven by the HPV in these distant anatomical areas.

Viral loads by quantitative RT-PCR display a wide variation with the majority of tumours harbouring more than 100 copies per cell indicating that viral loads in HPV-positive tumours are comparable to viral loads seen in cervical carcinomas. In only one sample (patient code 421) the viral load was below one copy per cell, reflecting the presence of HPV as concomitant infecting agent or a low number of tumour cells within the sample. Unfortunately, we were unable to obtain PCR grade RNA to analyse the viral expression, nevertheless this tumour was localized in the oral cavity where most of the tumours do not express viral mRNA $(8,26)$, suggesting that in this tumour the HPV involvement is rather as a passenger. HPV6 viral load was comparable to that of high-risk types, nevertheless the HPV6 involvement remains much less evident because even in a sample with 140 copies per cell (patient code 298) the expression of viral genes was not detected.

Molecular analysis strongly supports a causative role of HPV16 in a subset of HNSCC and suggests to introduce the study of viral integration and mRNA expression to define better these tumours, whereas the viral load seems not to add any other information.

With regard to the relationship of HPV presence with clinical-pathological parameters other than tumour site, we found a significant association of HPV status with the SCC differentiation grade, i.e. with poor-undifferentiated grades (G3-G4). Although some studies have found associations between advanced TNM stage at presentation and HPV positivity, more consistent results indicate that HPV-positive tumours tend to have a poorly differentiated histology, as in our case series (reviewed in ref. 5). A correlation of HPV status with non-drinkers and non-smokers was also detected but was not statistically significant. This finding is not in agreement with that reported in the literature, leading us to suppose some bias in the population recruitment or, most probably, in the collection of this information. In fact, this information was obtained from the clinical records and not from a dedicated questionnaire. The number of samples from which we obtained measurements of viral integration, expression, and load, renders it difficult, if not of low significance, to define the association of these viral characteristics with clinical-pathological parameters as well as to interpret the relevance of these events on clinical outcome.

Despite the relatively short follow-up length (range, 1-66 months) but considering that most of the disease progression and deaths occurred in the first 12 months of follow-up (data not shown), univariate and multivariate analysis were conducted on the relationships among HPV status, other known risk factors, and patient outcome. In univariate analysis a strong association of DFS and OS at a two-year interval was found with the differentiation grade of the tumour and the lymph node involvement. These parameters are well-known risk factors for a worse clinical outcome of the patients. This result renders more significance to the data from our population despite the short follow-up. Moreover, the multivariate analysis confirmed the independent association of the above parameters with the clinical outcome of the patients. Conversely, the lack of an impact of alcohol and tobacco carcinogens on survival may be explained by the already mentioned bias in the collection of this information. In univariate analysis all the other parameters including the HPV status were not related to clinical outcome, but in multivariate analysis the HPV status emerged as an independent risk factor for the OS at a twoyear interval.

Taken together our data indicate that a subset of HNSCC at oropharynx localization and in particular of tonsil area are strongly linked to HPV16 infection. In these tumours, physical status and viral expression, including the presence of mixed forms of transcriptionally active DNA genome, depict a landscape similar to that of cervix carcinoma. The low level of HPV18 infection and the different HPV susceptibility of the anatomical localizations may account for the difference in the frequency of HPV presence or integration in HNSCC with respect to the cervix carcinoma. The frequency in tonsil tumours reaches a value similar to that of the genital area, suggesting that the HPV acts as in the cervix tumours. The tonsil has squamous epithelium on the surface and reticulated epithelium in the crypts and may undergo metaplastic processes, producing an environment that may favour HPV infection and transformation, like in the cervical epithelium. It has been suggested that HPV-positive tonsillar carcinomas represent a separate tumour entity, which is less dependent on conventional HNSCC risk factors (29).

In conclusion, distinct pathological mechanisms for the malignant transformation in each single HN subsite should be taken into account and HPV detection should be considered a valid tool to distinguish subsets of oropharyngeal tumours. In the light of the forthcoming clinical use of an HPV vaccine in women, our results together with those reported in the literature indicate that by including male subjects in the target population of the vaccine a quarter of HNSCC and half of tonsil tumours could be prevented.

Finally, there are strong suggestions that HPV status could be a factor for the prognostic assessment of HNSCC.

\section{Acknowledgments}

This study was partially supported by Compagnia di San Paolo, Lega Tumori and Ministry of Health. C.R. and B.M. are recipients of Research Fellowships of Compagnia di San Paolo.

\section{References}

1. Parkin DM, Bray F, Ferlay J and Pisani P: Global cancer statistics, 2002. CA Cancer J Clin 55: 74-108, 2005.

2. Franceschi S, Bidoli E, Herrero R and Munoz N: Comparison of cancers of the oral cavity and pharynx worldwide: etiological clues. Oral Oncol 36: 106-115, 2000.

3. IARC Working group: IARC Monographs on the evaluation of carcinogenic risks to humans. Human Papillomaviruses. IARC Scientific Publication 64, International Agency for Research on Cancer, Lyon, 1995.

4. Kreimer AR, Clifford GM, Boyle P and Franceschi S: Human papillomavirus types in head and neck squamous cell carcinomas worldwide: a systematic review. Cancer Epidemiol Biomarkers Prev 14: 467-475, 2005.

5. Fakhry $\mathrm{C}$ and Gillison ML: Clinical implications of human papillomavirus in head and neck cancers. J Clin Oncol 24: 2606-2611, 2006.

6. Venuti A, Manni V, Morello R, De Marco F, Marzetti F and Marcante ML: Physical state and expression of human papillomavirus in laryngeal carcinoma and surrounding normal mucosa. J Med Virol 60: 396-402, 2000. 
7. van Houten VM, Snijders PJ, van den Brekel MW, Kummer JA, Meijer CJ, van Leeuwen B, Denkers F, Smeele LE, Snow GB and Brakenhoff RH: Biological evidence that human papillomaviruses are etiologically involved in a subgroup of head and neck squamous cell carcinomas. Int J Cancer 93: 232-235, 2001.

8. Wiest T, Schwartz E, Enders C, Flechtenmacher C and Bosch FX: Involvement of intact HPV 16 E6/E7 gene expression in head and neck cancers with unaltered p53 status and perturbed $\mathrm{pRb}$ cell cycle control. Oncogene 21: 1510-1517, 2002.

9. Badaracco G, Venuti A, Morello R, Muller A and Marcante ML: Human papillomavirus in head and neck carcinomas: prevalence, physical status and relationship with clinical/pathological parameters. Anticancer Res 20: 1301-1306, 2000.

10. Mellin H, Dahlgren L, Munck-Wikland E, Lindholm J, Rabbani H, Kalantari M and Dalianis T: Human papillomavirus type 16 is episomal and a high viral load may be correlated to better prognosis in tonsillar cancer. Int J Cancer 102: 152-158, 2002.

11. Koskinen WJ, Chen RW, Leivo I, Makitie A, Back L, Kontio R, Suuronen R, Lindqvist C, Auvinen E, Molijn A, Quint WG, Vaheri A and Aaltonen LM: Prevalence and physical status of human papillomavirus in squamous cell carcinomas of the head and neck. Int J Cancer 107: 401-406, 2003.

12. Klussmann JP, Weissenborn SJ, Wieland U, Dries V, Kolligs J, Jungehuelsing M, Eckel HE, Dienes HP, Pfister HJ and Fuchs PG: Prevalence, distribution, and viral load of human papillomavirus 16 DNA in tonsillar carcinomas. Cancer 92: 2875-2884, 2001.

13. Schlecht NF: Prognostic value of human papillomavirus in the survival of head and neck cancer patients: an overview of the evidence: Oncol Rep 14: 1239-1247, 2005.

14. Venuti A, Badaracco G, Rizzo C, Mafera B, Rahimi S and Vigili MG: Presence of HPV in head and neck tumours: high prevalence in tonsillar localization, J Exp Clin Cancer Res 23: 561-566, 2004.

15. Badaracco G, Venuti A, Sedati A and Marcante ML: HPV16 and HPV18 in genital tumors: Significantly different levels of viral integration and correlation to tumor invasiveness. J Med Virol 67: 574-582, 2002

16. Yoshinouchi M, Hongo A, Nakamura K, Kodama J, Itoh S, Sakai $\mathrm{H}$ and Kudo T: Analysis by multiplex PCR of the physical status of human papillomavirus type 16 DNA in cervical cancers. J Clin Microbiol 37: 3514-3517, 1999.

17. Rector A, Tachezy R and Van Ranst M: A sequence-independent strategy for detection and cloning of circular DNA virus genomes by using multiply primed rolling-circle amplification. J Virol 78: 4993-4998, 2004.
18. Sasagawa T, Minemoto Y, Basha W, Yamazaki H, Nakamura M, Yoshimoto H, Sakaike J and Inoue M: A new PCR-based assay amplifies the E6-E7 genes of most mucosal human papillomaviruses (HPV). Virus Res 67: 127-139, 2000.

19. Biswas C, Kell B, Mant C, Jewers RJ, Cason J, Muir P, Raju KS and Best JM: Detection of human papillomavirus type 16 earlygene transcription by reverse transcription-PCR is associated with abnormal cervical cytology. J Clin Microbiol 35: 1560-1564, 1997.

20. Klaes R, Woerner SM, Ridder R, Wentzensen N, Duerst M, Schneider A, Lotz B, Melsheimer P and von Knebel Doeberitz M: Detection of high-risk cervical intraepithelial neoplasia and cervical cancer by amplification of transcripts derived from integrated papillomavirus oncogenes. Cancer Res 59: 6132-6136, 1999.

21. Miguel RE, Villa LL, Cordeiro AC, Prado JC, Sobrinho J and Kowalski LP: Low prevalence of human papillomavirus in a geographic region with a high incidence of head and neck cancer. Am J Surg 176: 428-429, 1998.

22. Ha PK, Pai SI, Westra WH, Gillison ML, Tong BC, Sidransky D and Califano JA: Real-time quantitative PCR demonstrates low prevalence of HPV 16 in premalignant and malignant lesions of the oral cavity. Clin Cancer Res 8: 1203-1209, 2002.

23. Li W, Thompson CH, Xin D, Cossart YE, O'Brien CJ, McNeil EB, Gao K, Scolyer RA and Rose BR: Absence of human papillomavirus in tonsillar squamous cell carcinomas from Chinese patients. Am J Pathol 163: 2185-2192, 2003.

24. Li W, Thompson CH, Cossart YE, O'Brien CJ, Liu J, Scolyer RA, Carter JR, Dalrymple C and Rose BR: The site of infection and ethnicity of the patient influence the biological pathways to HPV-induced mucosal cancer. Mod Pathol 17: 1031-1037, 2004.

25. Syrjanen S: Human papillomavirus (HPV) in head and neck cancer. J Clin Virol 32S: S59-S66, 2005.

26. Herrero R: Chapter 7: Human papillomavirus and cancer of the upper aerodigestive tract. J Natl Cancer Inst Monographs 31: 47-51, 2003.

27. Snijders PJ, Meijer CJ, van den Brule AJ, Schrijnemakers HF, Snow GB and Walboomers JM: Human papillomavirus (HPV) type 16 and $33 \mathrm{E} 6 / \mathrm{E} 7$ region transcripts in tonsillar carcinomas can originate from integrated and episomal HPV DNA. J Gen Virol 73: 2059-2066, 1992

28. Ragin CC, Reshmi SC and Gollin SM: Mapping and analysis of HPV16 integration sites in a head and neck cancer cell line. Int J Cancer 110: 701-709, 2004.

29. Hafkamp HC, Manni JJ and Speel EJ: Role of human papillomavirus in the development of head and neck squamous cell carcinomas. Acta Otolaryngol 124: 520-526, 2004. 